\title{
Yapay Potansiyel Alan ile Otonom Araçların Kavşak Geçiş Önceliğinin Belirlenmesi
}

\author{
Abdullah Ersan Oğuz ${ }^{1 *}$, Mustafa Emre Aydemir ${ }^{2}$ \\ 1* İstanbul Esenyurt Üniversitesi, Mühendislik Mimarlık Fakültesi, Elektrik Elektronik Mühendisliği Bölümü, İstanbul, Türkiye, (ORCID: 0000-0003-3413-7876), \\ abdullahersanoguz@esenyurt.edu.tr \\ 2 İstanbul Esenyurt Üniversitesi, Mühendislik Mimarlık Fakültesi, Elektrik Elektronik Mühendisliği Bölümü, İstanbul, Türkiye, (ORCID: 0000-0002-9285-5115), \\ mustafaaydemir@esenyurt.edu.tr
}

(International Conference on Design, Research and Development (RDCONF) 2021 - 15-18 December 2021)

(DOI: 10.31590/ejosat.1040657)

ATIF/REFERENCE: Oğuz, A. E. \& Aydemir, M. E. (2021). Yapay Potansiyel Alan ile Otonom Araçların Kavşak Geçiş Önceliğinin Belirlenmesi. Avrupa Bilim ve Teknoloji Dergisi, (32), 197-206.

$\ddot{O} \mathbf{z}$

Otonom Araç Sistemlerinin kullanımına yönelik çalışmalar gün geçtikçe artmaktadır. Otonom araçların arazi kullanımı denemelerinin yanında yaya ve insanlı araç trafiğinin de olduğu şehir içi trafiğinde kullanımına yönelik değişik yöntem ve uygulamar devam etmektedir. Otonom aracın karma trafik içerisinde, kendine ve diğer trafik unsurlarına zarar vermeden hareket edebilmesi çözüm bekleyen en önemli problemlerin başında gelmektedir. Yapılan çalışmalarda otonom aracın güvenli seyrüseferi için mantıksal karar vericiler ve pek çok kural tabanı oluşturulmakta ve sürücü davranışı modellenmeye çalışılmaktadır. Bu çalışma kapsamında potansiyel fonksiyonlar ile modellenmiş yol ve araçlardan oluşan kavşak yapısında hareket eden otonom araçların birlerine çarpmadan şerit takibi yaparak kavşak içerisinde geçiş öncelikleri oluşturması ve hedefledikleri noktaya güvenli şekilde ulaşmaları incelenmiştir. Çalışmanın amacı mantıksal karar verme karmaşık yapısını, oluşturulan yapay potansiye alan haritası ile sağlamaktır. Yapay potansiyel alan yaklaşımı otonom araç uygulamalarında yol planlaması, şerit takibi uygulamalarında başvurulan tekniklerden birisidir. $\mathrm{Bu}$ çalışma ile yapay potansiyel alan yaklaşımlı yol ve şerit ile kavşak içerisinde çarpışma ihtimali olan aracın hareketli(dinamik) engel olarak modellenmesi de birleştirilerek çözüm aranmıştır. Çalışma sonucunda görülmüştür ki mantıksal karar vericilerin kullanılmasının yerine, mantıksal kural tabanına uygun olarak hazırlanmış/optimize edilmiş yapay potansiyel alan kullanılması başarılı sonuçlar vermiştir. Çalışmada yapay potansiyel alan oluşturulması için harmonik ve gaussien fonksiyonların kullanımı ile istek dişı local minimaların oluşması engellenmiştir.

\section{Determination of Intersection Transition Priority of Autonomous Vehicles with Artificial Potential Field}

\begin{abstract}
Studies on the use of Autonomous Vehicle Systems are increasing day by day. In addition to the land use trials of autonomous vehicles, various methods and practices are continuing for the use of pedestrian and manned vehicle traffic in urban traffic. The ability of the autonomous vehicle to move in mixed traffic without harming itself and other traffic elements is one of the most important problems waiting for a solution. In the studies, logical decision makers and many rule bases are created for safe navigation of autonomous vehicles and driver behavior is tried to be modeled. Within the scope of this study, autonomous vehicles moving in the
\end{abstract}

* Sorumlu Yazar: abdullahersanoguz@ esenyurt.edu.tr 
intersection structure, which consists of roads and vehicles modeled with potential functions, follow the lane without hitting each other and create transition priorities in the intersection and reach their target point safely. The aim of the study is to provide the logical decision making complex with the artificial potential area map created. Artificial potential field approach is one of the techniques used in road planning and lane tracking applications in autonomous vehicle applications. In this study, a solution was sought by combining the artificial potential field approach road and lane with the vehicle that is likely to collide in the intersection as a moving (dynamic) obstacle. As a result of the study, it was seen that instead of using logical decision makers, the use of artificial potential field prepared/optimized in accordance with the logical rule base gave successful results. In the study, the formation of undesired local minimas was prevented by the use of harmonic and Gaussian functions to create an artificial potential field..

Keywords: Navigation, Artificial Potential Field, Path Planning, Obstacle Avoiding.

\section{Giriş}

Robotik ve otonom araçlar konusunda çalışmalar yapan araştırmacılar için, otonom İnsansız Kara Araçlarının (UGV) yol planlaması oldukça zor ve ilgi çekici bir çalışma alanıdır. Robot ve kara araçlarının yol planlaması hem optimum yolun bulunması hemde engellerden ve diğer araçlardan kaçınılmasını gerektirmektedir. Robot ve kara araçlarının yol planlamasının yapılması için Yapay Potansiyel Alan (APF-artificial potential field) kullanımı uzun yıllardır uygulanmaktadır (Reyes \& Tanner, 2014; Shi at al., 2007; Sisli \& Temeltas, 2008; Nair at al., 2015). Otonom kara araçları için şerit değiştirme, şerit takibi ve kavşak geçiş önceliğinin belirlenmesi ayrı birer çalışma alanı olarak göze çarpmaktadır.

Yapay potansiyel alanlar basit denklemlere dayalı, dinamik olarak hesaplanabilir olması nedeniyle araç yol planlamalarında yaygın olarak kullanılan bir yöntemdir (Reyes \& Tanner, 2015; Shi at al., 2007; Sisli \& Temeltas, 2008; Nair at al., 2015). Yapay Potansiyel alan ilk olarak hedef ve itici potansiyel oluşturarak mobil robot kontrolü yapmak için Khatib tarafından ortaya konulmuştur (Khatib, 1986). Yapay Potansiyel Alan hesaplamalarında kullanılan formüller hedef dışında yerel minimumlar oluşturabilmektedir. $\mathrm{Bu}$ durumda araç hedef yerine yerel minimumlara yönelebilmekte ve istenilen hedefe ulaşılamamasına neden olabilmektedir. Kodistcek sınırlandırılmış alan içerisinde otonom aracın daima başlangıç noktasından hedefe ulaşmasını sağlayacak fonksiyonlar oluşturabilmiştir (Koditschek, 1987). Krough ve Thorpe tarafindan (Krough \& Thorpe, 1986) genel ve yerel yol planlaması yapabilen metod ortaya konulmuş, gerçek sensör bilgisi kullanan robotlar üzerinde potansiyel alanların uygulanmas1 Brooks (Brooks, 1986) ve Arkın (Arkin, 1987) tarafından yapılmıştır. Connolly, yapay potansiyel alan hesaplamalarında harmonik fonksiyonları kullanmıştır (Connoly \& Grupen, 1982; Connoly, 1997). Araçlar için şerit ve yolların potansiyel alanlarla tanımlanması ile şerit değiştirme (Knoop \& Buisson, 2015; Wang \& Coifman ,2008) ve şerit takibi (Huang \& Houshangi ,2009; Apostoloff \& Zelinsky. ,2003) davranışı modellenmiştir.

Çalışmada yapay potansiyel alanının tanımlanması için, yerel minimum durumu oluşturmayacak şekilde iki boyutlu üstel harmonik fonksiyonlar kullanılmıştır. Yol planlaması için hedefe yönelmeyi sağlayacak şekilde düzgün eğim ve çeken yapay potansiyel alan oluşturulup alan içerisine şerit takibi için panel yapısında Gausyen sabit engeller ve diğer araçlar için dairesel hareketli engeller yerleştirilmiştir. Oluşturulan yapay potansiyel alan haritası ile araçların belirlenmiş hedeflerine kavşak içerisinde birbirlerine çarpmayacak şekilde yol vererek ulaşmalarını sağlanmıştır. Yapay potansiyel alanın gradient vektörleri hesaplanarak, bu vektörler ile araçların hareketi sağlanmış ve araç modeli olarak basit noktasal yüklü araç dinamiği kullanılmıştır.

\section{Yapay Potansiyel Alanlar}

Yapay potansiyel alanlar basit denklemlere dayalı ve dinamik olarak hesaplanabilir olarak oluşturulmaktadır. Yapay potansiyel alanın oluşturulması için hedef/çeken alan fonksiyonu, düzgün akış fonsiyonu, şerit/yol takibini sağlayacak şekilde panel fonksiyonu ve araçların engel olarak tanımlanması için iten alan fonksiyonu kullanılmakta ve fonksiyonların aynı noktaya etkileri gradientlerinin toplanması ile hesaplanmaktadır (Oguz \& Duymaz, 2016).

Aracın başlangıç noktası ile hedef noktası arasında oluşturulan potansiyelin sabit değiştiği alana düzgün akış denilir. Başlangıç noktası ile hedef noktası arasındaki açı $\alpha$ olmak üzere denklem (1) ile hesaplanır (Şekil 1).

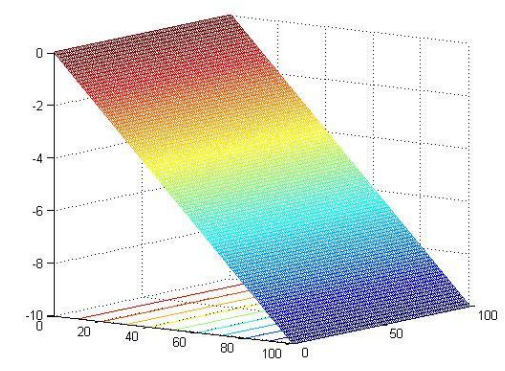

Şekil 1 Düzenli Yapay Potansiyel Alan

$$
\emptyset_{u}=-\lambda_{u}(x \cos \propto+y \sin \propto)
$$

Düzgün akış, toplam potansiyeli sıfır olan noktalarda aracın hedefe doğru yönelmesini sağlar. $\lambda_{u}$ düzgün akışın gücünü verir.

Çeken potansiyel alan için harmonik fonksiyon kullanılmıştır. $\mathrm{Bu}$ fonksiyon ile çeken alan kuvvetinin exponansiyel olarak hedefe doğru artması sağlanmaktadır. Çeken potansiyel alan denklem (2) de verilmiş olup burada $\lambda_{g}$ çeken alanın gücünü göstermektedir.

$$
\emptyset_{g}=-\frac{\lambda_{g}}{2 \pi} \ln \left(x^{2}+y^{2}\right)
$$




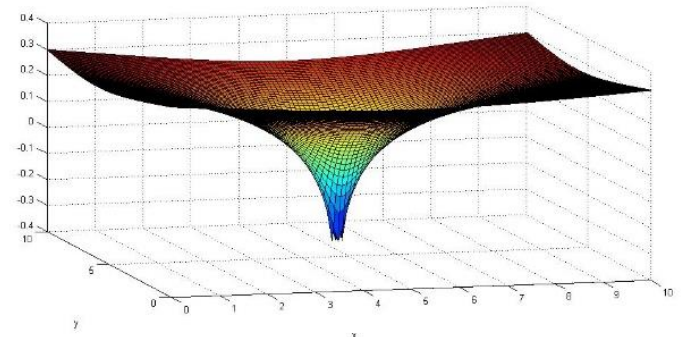

Şekil 2 Çeken Potansiyel Alan

Çalışmamızda iten potansiyel alan olarak iki boyutlu Gauss fonksiyonu kullanılmıştır.

Diğer aracın engel olarak tanımlanması için kullanılan iten alan fonksiyonu aracın şekline göre eliptik olarak tanımlanmıştır. İten alan fonksiyonu denklem (3) de verilmiş olup $\lambda_{c}$ iten alan gücünü, $\sigma_{x}$ ve $\sigma_{y}$ ise $\mathrm{x}$ ve $\mathrm{y}$ eksenindeki yayılımını göstermektedir.

$$
\emptyset_{c}=\lambda_{c} \exp -\left(\frac{x^{2}}{\sigma_{x}^{2}}+\frac{y^{2}}{\sigma_{y}^{2}}\right)
$$

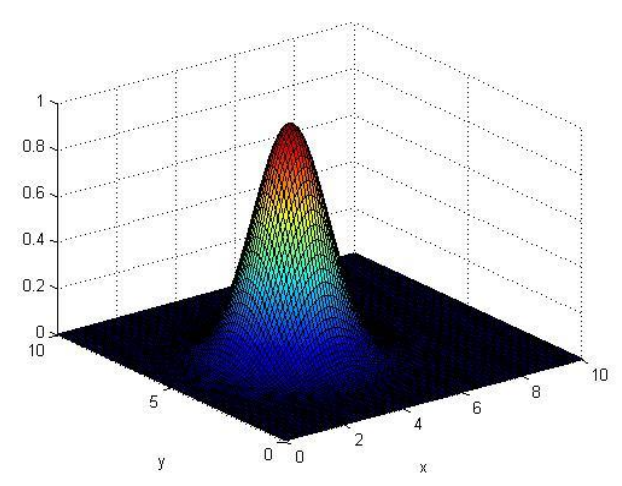

Şekil 3 İten Potansiyel Alan

Yol kenarlarının ve şeritlerin modellenmesi için gaussien temelli panel potansiyel alan kullanılmıştır. $\mathrm{Bu}$ fonksiyon ile şerit ortasında doğal bir minumum düzlem oluşturulmuş ve aracın bu düzlem üzerinde hareketi sağlanmıştır. Araç yol kenarına veya şerit sınırına yaklaştığında gradient vektörü aracın yeniden şerit ortasına itilmesini sağlamaktadır. Panel fonksiyonu denklem (4) de verilmiş olup $\lambda_{l}$ panel itme gücünü, $\sigma$ ise eksenindeki yayılımını göstermektedir.

$$
\emptyset_{l}=\lambda_{l} \exp -\left(\frac{y^{2}}{\sigma^{2}}\right)
$$

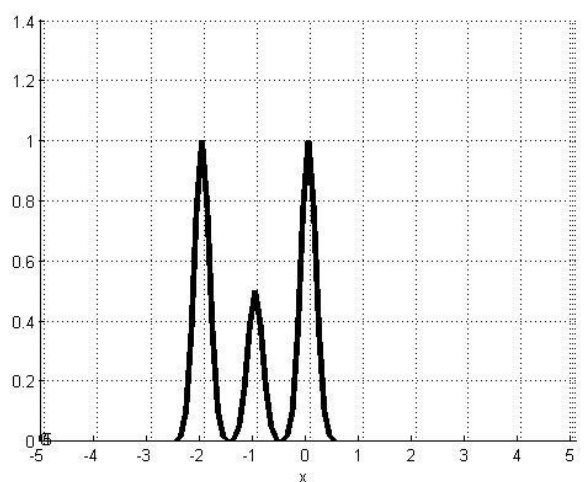

Şekil 4 Panel Potansiyel Alanın ile yol ve şerit kesit görünümü

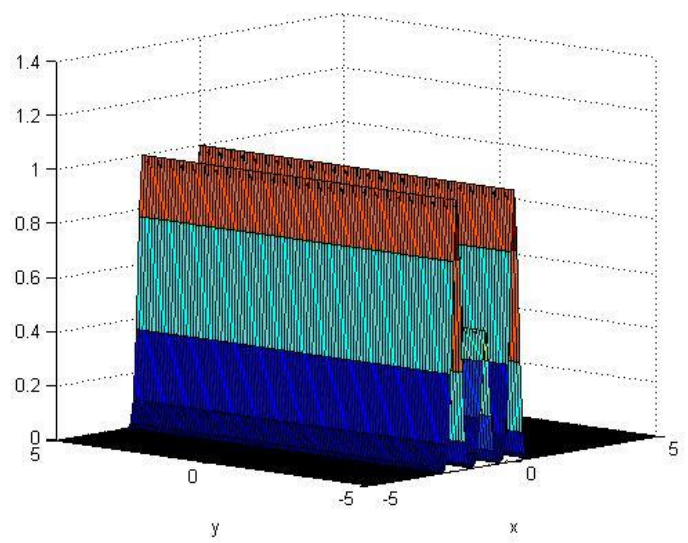

Şekil 5 Gausyen panel Potansiyel Alan ile yol ve şerit modellenmesi

Harita üzerinde yer alan şerit, düzgün akış, araç/engel ve hedef potansiyel alanları ayrı ayrı oluşturulduktan sonra, fonsiyonların toplamsallık özelliğinden faydanılarak her noktadaki etkileri toplanabilir ve böylece toplam potansiyel alan formul (5) de gösterildiği şekilde hesaplanır

$$
\emptyset=\emptyset_{u}+\emptyset_{g}+\emptyset_{c}+\emptyset_{l}
$$

\section{Araç Modeli}

Kara aracının yapay potansiyel alan içinde hareketini en kolay modelleme yöntemi aracı, aracın ağırlık merkezinde noktasal yük olarak kabul etmektir. Noktasal yükün hareketinin basitliği ve hesaplama kolaylığı APF çalışmalarında tercih edilmesine neden olmaktadır. Noktasal yüklü araç iki eksende serbest olarak hareket edebildiği için hareket kısıtlaması olan araç modellerinin gösteriminde çeşitli eksiklikler yaratsa da çalışmamızın ana konusu APF olduğından ve araç modeli ile hareketi benzetim uzayı için kullanıldığından bu eksiklikler dikkate alınmamıştır.

Noktasal yüklü aracın basit dinamik denlemini Newton'un ikinci yasasından

$$
F=M \frac{d V}{d t}
$$

yazabiliriz.

$$
M \frac{d V}{d t}=-K_{f} \partial P-K V
$$

Nokta yüklü aracın hızı V'nin konumun(x) birinci türevi ve ivmesinin ikinci türevi olduğu bilindiğinden $\ddot{x}$ şeklinde yerine yazarak denklemi düzenlersek

$$
\ddot{x}=M^{-1}\left(-K_{f} \partial P-K \dot{x}\right)
$$


Elde edilir. Burada $\partial P$ Yapay Potansiyel alan gradient vektörünü, $\mathrm{M}$ kütleyi, $K_{f}, K$ 'da sabit katsayıları göstermektedir.

\section{Benzetim}

Çalışmada 100x100 metrelik alan içerisinde gidiş ve geliş şeritlerinden oluşan merkezi $(50,50)$ noktasında olan ve geçiş üstünlüğü sağlamayan Şekil 6'da görülen dört yol kavşağ 1 oluşturulmuştur. Araçların şerit takibi için panel fonksiyonları kullanılmıştır. Çalışmada 3 farklı senaryo denenmiştir.

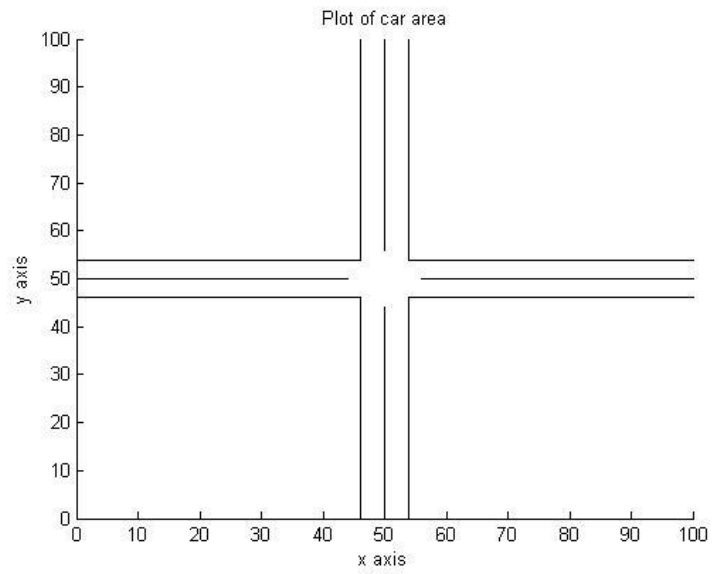

Şekil 6 Kavşak yapısı

\subsection{Senaryo 1}

İlk senaryoda; birinci aracın (Car1) daha önce kavşağa giren ikinci araca (Car2) soldan çarptığı durum oluşturulmuştur. Buna uygun olarak başlangıç noktaları birinci araç için $(31,48)$, ikinci araç için $(90,52)$ ve başlangıç hızları her iki araç için $10 \mathrm{~m} / \mathrm{sn}$ seçilmiştir. Araçların potansiyel etkisi hesaba katılmadığında oluşan durum. Şekil 7'de görülmektedir.

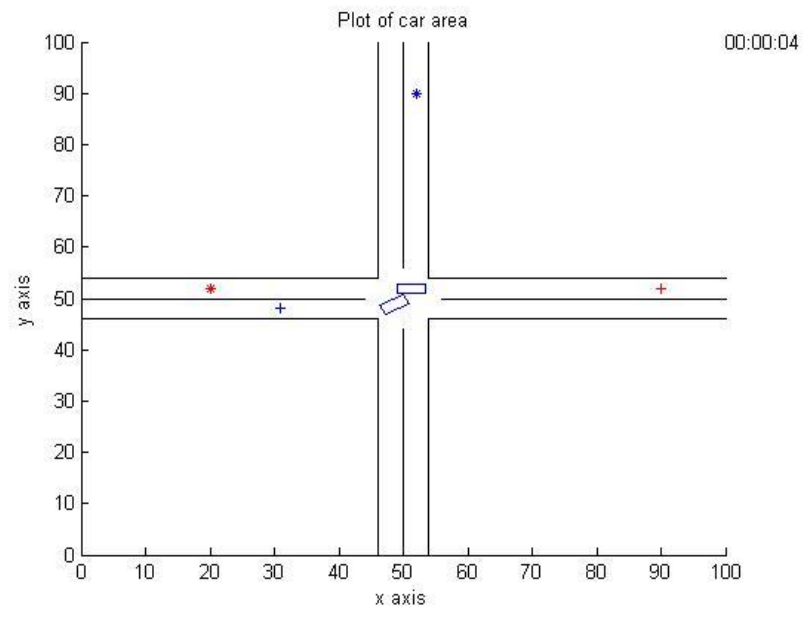

Şekil 7 Senaryo 1 çarpışma anı

Araçların birbirlerini etkilemedikleri durumda araç hız grafikleri Şekil 8'deki gibi oluşmaktadır. Grafikte birinci araç hızı kırmızı ikinci araç hızı siyah ile gösterilmektedir.

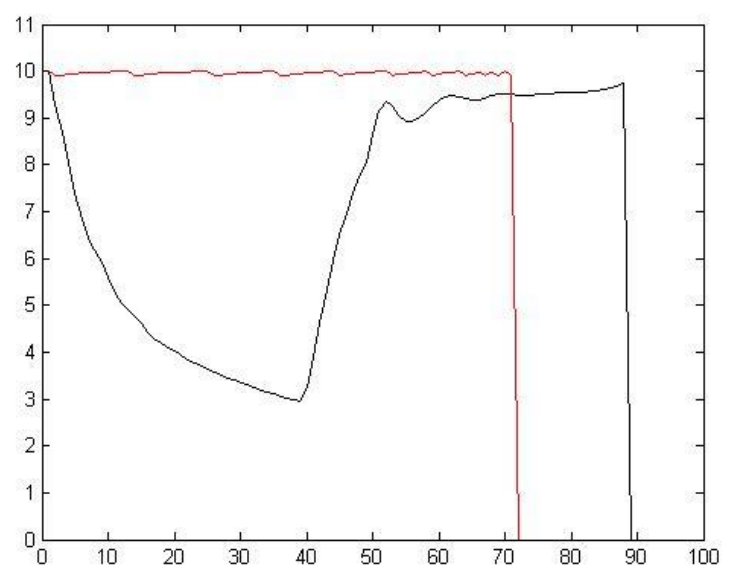

Şekil 8 Senaryo 1 çarpışma ve yol verme olmaması durumunda araç hız grafikleri.

Senaryoda araç potansiyelleri hesaplamalara dahil edildiğinde birinci aracın hızlı bir şekilde kavşağa giren ve yoluna dönüş yapmadan devam eden ikinci araca çarpmadan durarak yol verdiği ve ikinci aracın geçişi sonrasında güvenli bir şekilde yoluna devam ettiği Şekil 9'da görülmektedir.

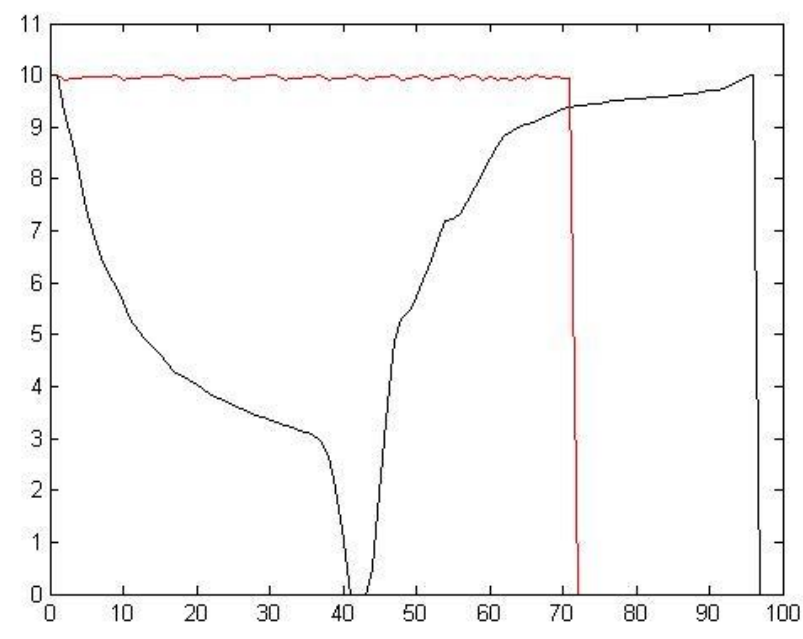

Şekil 10 Senaryo 1 araç hız grafiği

Birinci senaryoda araçlara ait Şekil $10^{`} \mathrm{da}$ verilen hız grafiği incelendiğinde kavşağa önceden giren ve yoluna devam eden ikinci araca çarpmamak ve yol vermek için birinci aracın hızını sıfıra düşürerek durduğu ve ikinci aracın geçişinden sonra yoluna devam ettiği böylece kavşağa önce giren araca yol vererek çarpışmayı engellediği görülmektedir. 
European Journal of Science and Technology
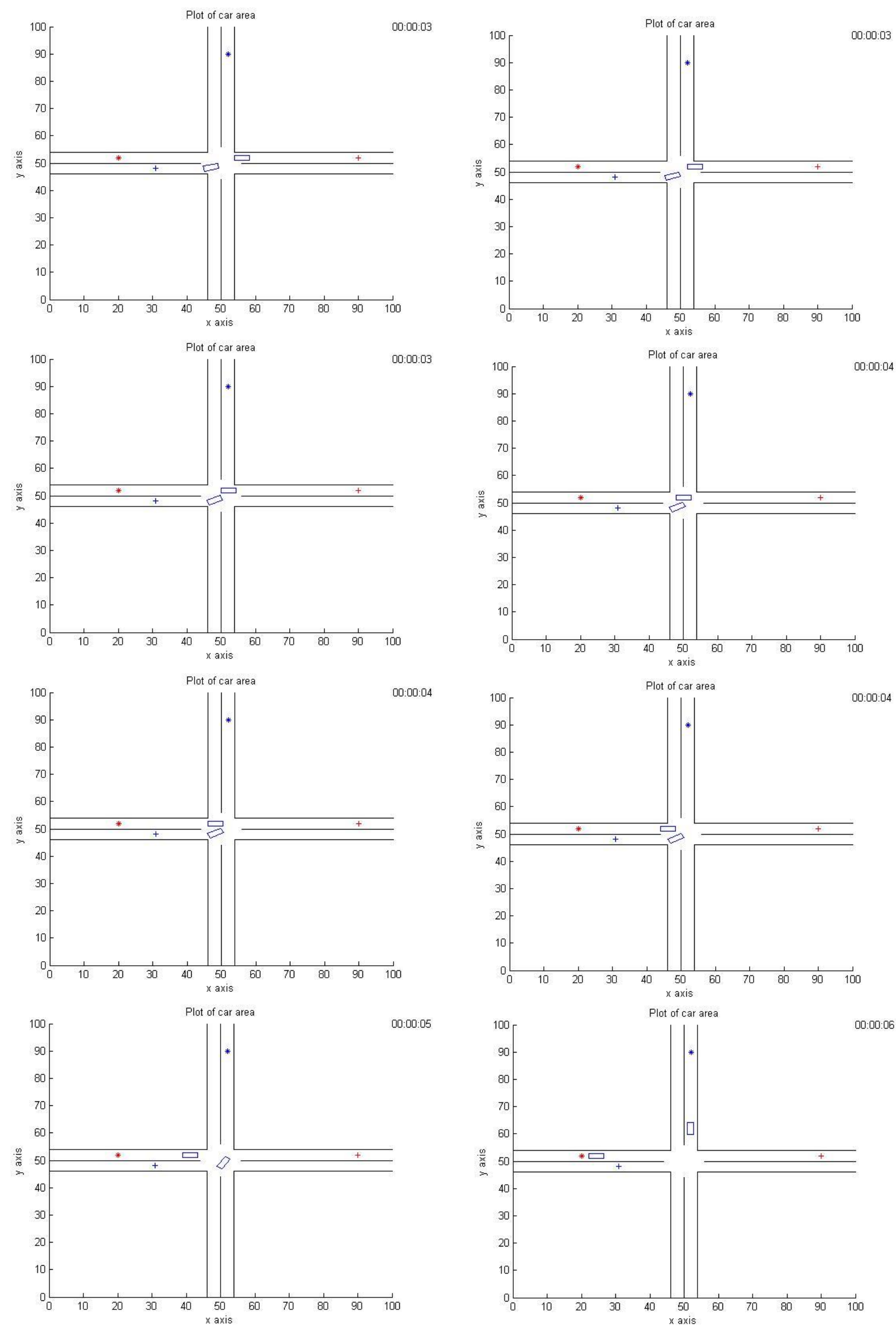

Şekil 9 Senaryo 1 araç pozisyonları 


\subsection{Senaryo 2}

$\mathrm{Bu}$ senaryoda ikinci aracın daha önce kavşağa giren ve dönüşünü tamamlamak üzere olan birinci araca sağdan çarptığ 1 durum incelenmiştir. Senaryonun gerçekleştirilmesi için birinci aracın başlangıç noktası $(35,48)$, ikinci aracın başlangıç noktası $(94,52)$ ve başlangıç hızları $10 \mathrm{~m} / \mathrm{sn}$ seçilmiştir. Araçların potansiyel etkisi hesaba katılmadığında oluşan çarpışma anı Şekil 11 de gösterilmiştir.

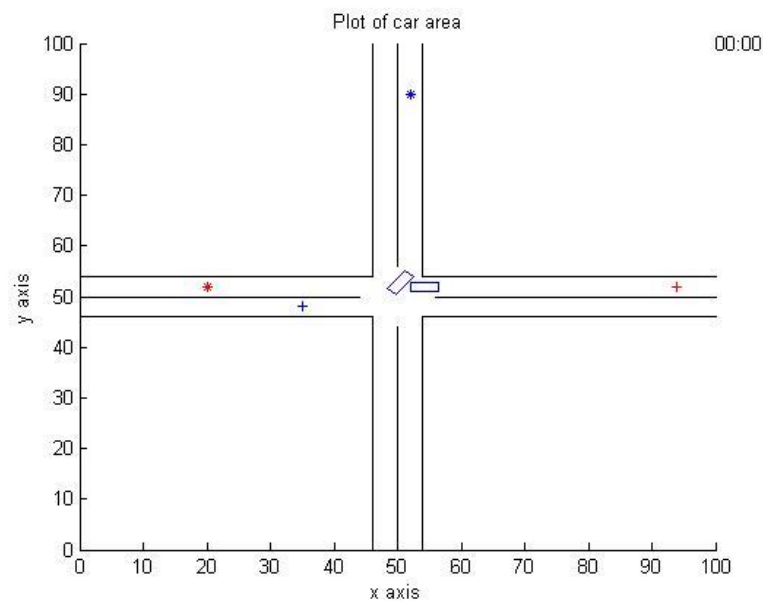

Şekil 11 Senaryo 2 çarpışma anı

Araçların birbirlerini etkilemedikleri durumda araç hız grafikleri Şekil 12'deki gibi oluşmaktadır. Grafikte birinci araç hızı kırmızı ikinci araç hızı siyah ile gösterilmektedir.

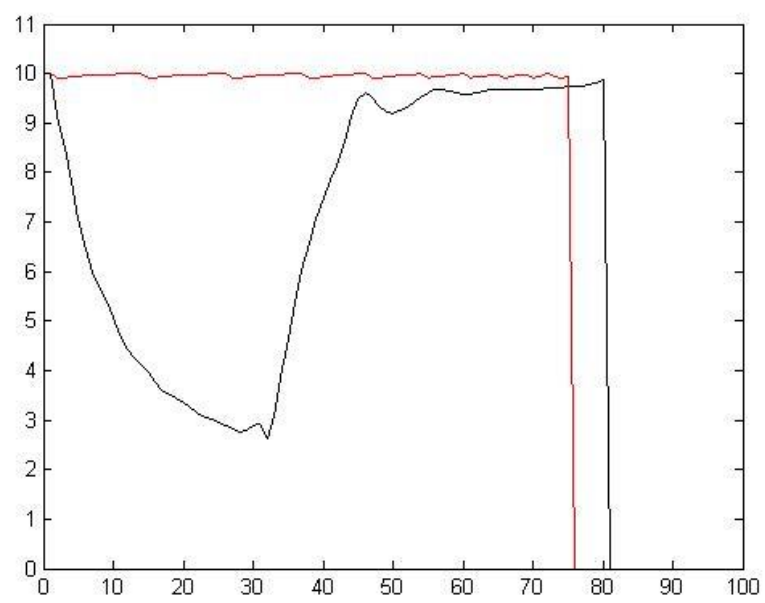

Şekil 12. Senaryo 2 çarpışma ve yol verme olmadan hız grafiği

İkinci senaryoda araç potansiyel alanları hesaplamaya dahil edildiğinde ikinci aracın kavşağa giren ve dönüşünü tamamlamak üzere olan birinci araca çarpmadan yavaşlayarak durduğu ve birinci aracin geçişinden sonra güvenli bir şekilde yoluna devam ettiği Şekil 13'de görülmektedir.

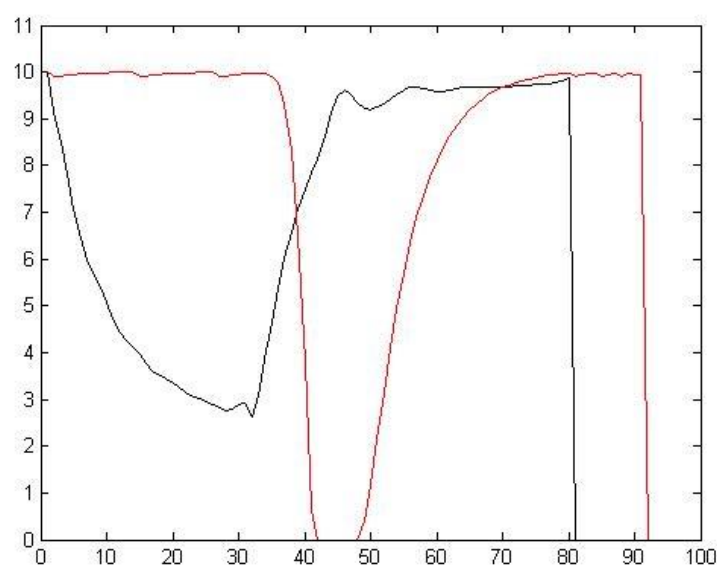

Sekil 14 Senaryo 2 araç hız grafikleri

İkinci senaryoda araç potansiyel alanlarının hesaplamaya

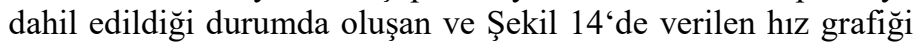
incelendiğinde kavşağa önce giriş yapan ve yoluna devam eden birinci araca çarpmamak için ikinci aracın hızını sıfıra düşürerek durduğu ve birinci aracın geçişinden sonra yoluna devam ettiği böylece kavşağa önce giren araca yol vererek çarpışmayı engellediği görülmektedir.

\subsection{Senaryo 3}

$\mathrm{Bu}$ senaryoda ikinci aracın önünde olan birinci aracın dönüş yapmak için yavaşlaması nedeniyle ikinci aracın arkadan çarptığ 1 durum incelenmiştir. Senaryoya uygun olarak araç başlangıç noktaları birinci araç için $(35,48)$, ikinci araç için $(05,48)$ ve başlangıç hızları $10 \mathrm{~m} / \mathrm{sn}$ seçilmiştir. Araçların potansiyel etkisi hesaba katılmadığında oluşan durum Şekil 15'de ve araçla ait hız grafiği ise Şekil 16'da verilmiştir.

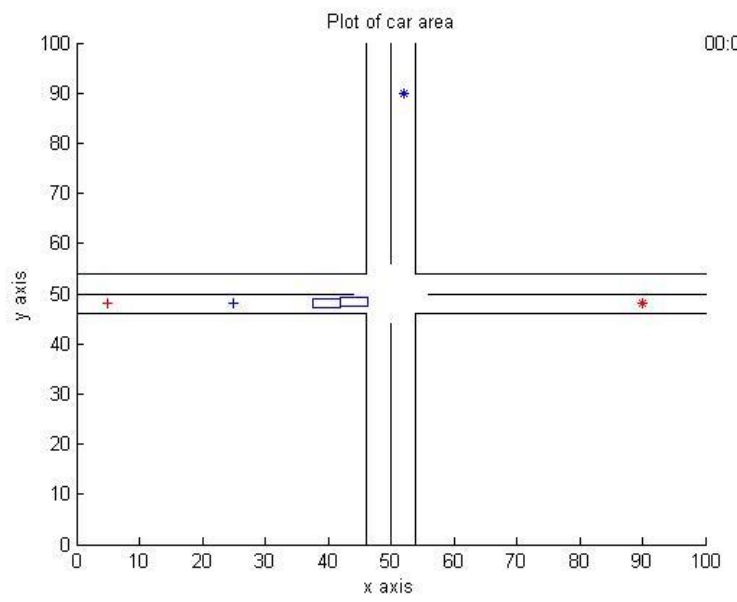

Şekil 15. Senaryo 3 çarpışma anı 
European Journal of Science and Technology
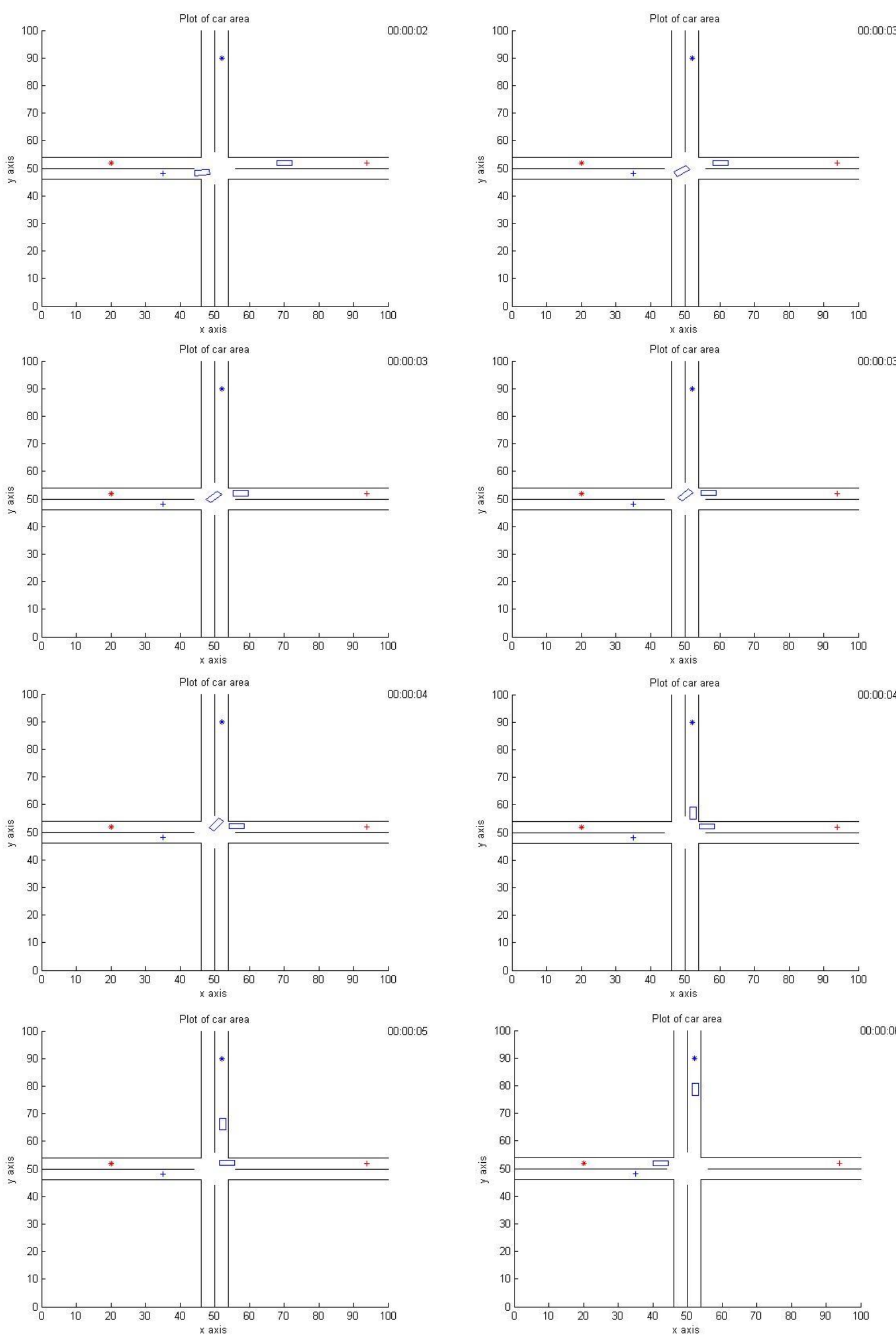

Şekil 13 Senaryo 2 araç pozisyonları 
Avrupa Bilim ve Teknoloji Dergisi
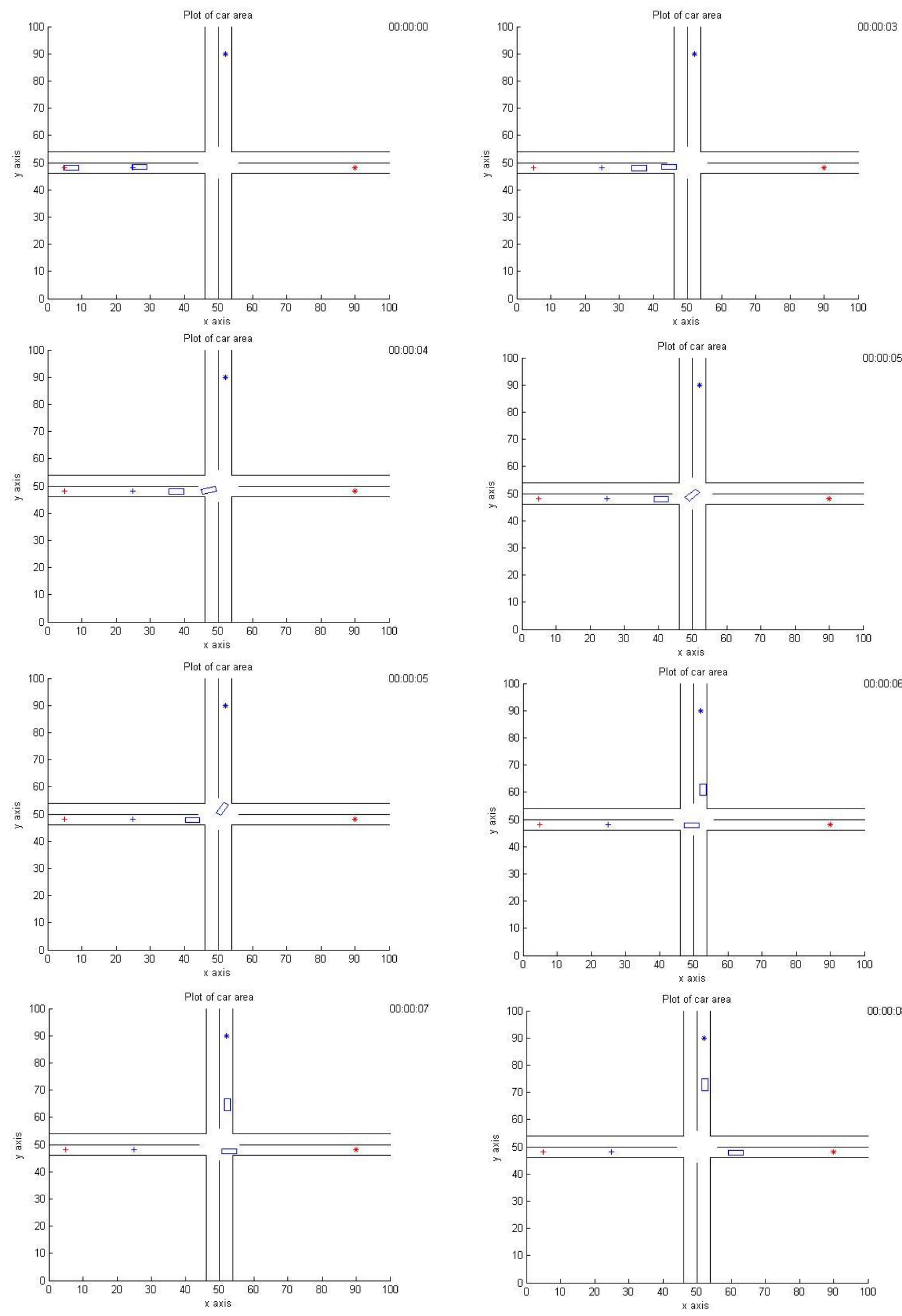

Şekil 17 Senaryo 3 araç pozisyonları 


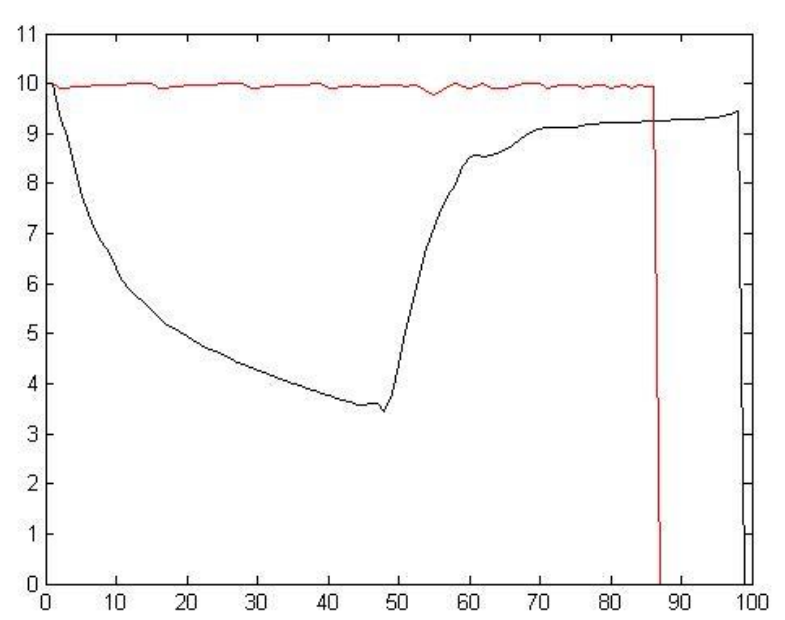
grafiği

Şekil 16. Senaryo 3 çarpışma ve yol verme olmadan hız

Üçüncü senaryoda araç potansiyel alanları hesaplamaya dahil edildiğinde ikinci aracın, yavaşlayarak dönüş yapmak için kavşağa giren birinci araca çarpmadan, yavaşladığı ve birinci aracın dönüşünü tamamlaması sonrasında hızlanarak yoluna devam ettiği Şekil 17'de görülmektedir.

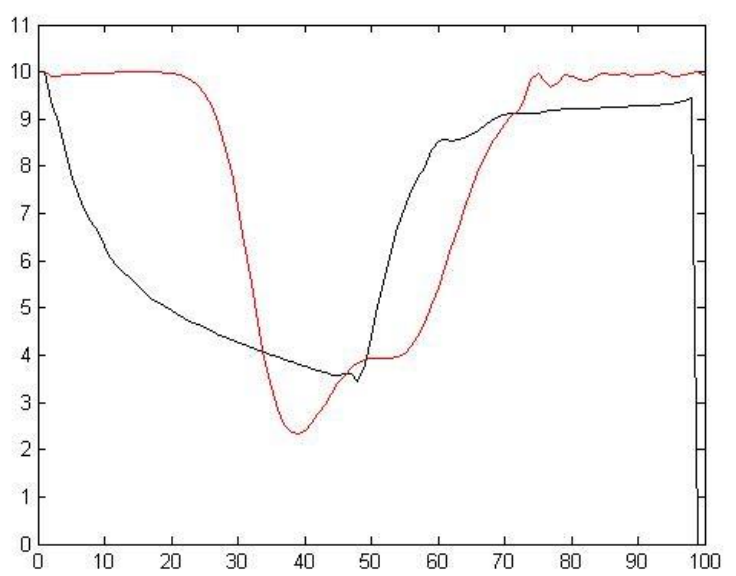

\section{Şekil 18 Senaryo 3 araç hız grafiği}

Üçüncü senaryoda araçların hız grafiği Şekil 18'de verilmiştir. Araçlara ait hız grafiği incelendiğinde önde olan ve kavşağa yaklaştıkça dönüş için yavaşlayan birinci araca çarpmamak için ikinci aracın hızını birinci araca uygun şekilde azalttığı ve birinci aracın dönüşü sonrasında hızını artırarak güvenli bir şekilde yoluna devam ettiği görülmektedir.

\section{Sonuç}

$\mathrm{Bu}$ çalışmada harmonik ve Gausyen fonksiyonlar kullanılarak oluşturulmuş basit geçiş önceliği olmayan kavşak yapısı yapay potansiyel alanla modellenmiş ve bu sistemde hareket eden iki aracın şerit takibi yaparak birbirlerine çarpmadan hedeflerine ulaşıp ulaşamayacağı incelenmiştir. Çalışmada yol ve şerit için Gausyen panel fonksiyonu, araçların birbirini engel olarak görmesi için ise dinamik iki boyutlu Gauss fonksiyonu kullanılmıştır. Oluşturulan yapay potansiyel alanın istenmeyen lokal minimum noktalara sahip olmadığı garanti edilmiştir. Çalışmanın güvenirliliğini artırmak için üç senaryo MATLAB ortamında denenmiştir. Benzetimler sonucunda herhangi bir mantıksal karar verme olmadan sadece yapay potansiyel alan kullanılarak araçların güvenli şekilde şerit takibi yaparak birbirlerine çarpmadan, geçiş önceliği vererek hedeflerine ulaşabilecekleri görülmüştür.

Çalışmada elde edilen benzetim sonuçları; Gausyen panel fonksiyonu ile modellenen basit kavşaklı yol sistemi ve dinamik araç/engel potansiyel alan fonksiyonları kullanılarak otonom araçların hedeflerine şerit takibi yaparak ve diğer araca çarpmadan ulaşmasının mümkün olabileceğini göstermiştir.

Yapay potansiyel alan kullanımında temel haritanın oluşturulması ve iten/çeken alan güçlerinin optimize edilmesi uygulamanın başarısı için önemlidir. Gelecek çalışmalarda bu optimizasyonun harita değişimine uygun olarak yenilenmesi denenebilir. Çalışmada harita üzerinde iki aracın bulunduğu ve yolların iki şeritli olduğu kabul edilmiştir. Haritanın ölçeğinin büyütülmesi, değişik sayıda şeritlerden oluşan farklı yapılarda yolları içeren kapsamlı bir şehir haritasının ikiden fazla aracı içerecek şekilde oluşturulması ve optimize edilmesi ile şehir içi trafiğinde otonom araçların yapay potansiyel alanla oluşturulmuş modeli kullanarak güvenli bir şekilde hedeflerine varmaları sağlanabilir.

\section{Kaynakça}

Apostoloff, N., \& Zelinsky, A., (2003). Robust vision based lane tracking using multiple cues and particle filtering. Intelligent Vehicles Symposium, Pages: 558 - 563,

Arkin R.C., (1987). Towards cosmopolitan robots: Intelligent navigation in extended man-made environments. Technical reports COINS Department, University of Massachusetts.

Brooks R.A., (1986). A robust layered control systems for a mobile robot. IEEE Journal of Robotics and Automation, Vol. 2, No.1, pp: 14-23.

Connoly C.I., \& Grupen R.A., (1992). Applications of Harmonic Functions to Robotics. University of Massachusetts at Amherst Thesis.

Connoly C.I., (1997). Harmonic functions and collision probabilities. International Journal of Robotics Research, vol. 16-4, pp:497-507.

Huang, X., \& Houshangi, N., (2009). A vision-based autonomous lane following system for a mobile robot. Systems, Man and Cybernetics, SMC 2009. IEEE International Conference, Pages: 2344 - 2349.

Khatib O., (1986). Real time obstacle avoidance for manipulators and mobile robots. International Journal of Robotics Research Vol. 5-1, pp: 90-99.

Knoop, V.L., \& Buisson, C., (2015). Calibration and validation of probabilistic discretionary lane-change models. IEEE Transactions on Intelligent Transportation Systems, , Volume: 16, Issue: 2 Pages: $834-843$.

Koditschek D.E., (1987). Exact robot navigation by means of potential functions: Some topological considerations. IEEE In International Conference on Robotics and Automation, pp: $1-6$.

Krough B.H., \& Thorpe, C.E., (1986). Integrated path planning and dynamic steering control for aautonomous vehicles. IEEE International Conference on Robotics and Automation, pp: 1664-1669. 
Nair, R.R., Behera, L., Kumar, V., \& Jamshidi, M., (2015). Multisatellite formation control for remote sensing applications using artificial potential field and adaptive fuzzy sliding mode control. IEEE Systems Journal. Volume: 9, No: 2, pp: 508 - 518.

Oguz A.E., \& Duymaz E., (2016). Artificial potantial field based autonomus UAV fligh in dynamic environment. 16th AIAA Aviation Technology, Integration, and Operations Conference, Doi: 10.2514/6.2016-3454

Reyes, L.A.V.; \& Tanner, H.G., (2015). flocking, formation control, and path following for a group of mobile robots. IEEE Transactions on Control System Technology Vol.23, Issue 4, 1268-1282.

Shi C., Zhang M., \& Peng J., (2007). Harmonic potential field method for autonomous ship navigation. Shanghai Maritime University Thesis China.

Sisli U.Y., \& Temeltas H., (2008). Decentralized formation control of multi vehicles systems with non-holonomic constraints using artificial potential field. 17th IFAC World Congress, Vol.17, 6815-6820,

Wang, C.; \& Coifman, B., (2008). The effect of lane-change maneuvers on a simplified car-following theory. IEEE Transactions on Intelligent Transportation Systems, Volume: 9, Issue: 3, Pages: $523-535$, 